\title{
Adsorption on Activated Carbon from Olive Stones: Kinetics and Equilibrium of Phenol Removal from Aqueous Solution
}

\section{Thouraya Bohli ${ }^{1 *}$, Nuria Fiol ${ }^{2}$, Isabel Villaescusa ${ }^{2}$ and Abdelmottaleb Ouederni ${ }^{1}$}

${ }^{1}$ Laboratory of Research: Engineering Processes and Industrials Systems (LR11ES54), National School of Engineers of Gabes, University of Gabes, St Omar Ibn Elkhattab, 6029 Gabes, Tunisia

${ }^{2}$ Department d'Enginyeria Quimica, Agraria i Tecnologia Agroalimentaria,Universitat de Girona, Avda Lluis Santolo, 17003 Girona, Spain

\begin{abstract}
Activated carbon is prepared with chemical activation of olive stones, by using $\mathrm{H}_{3} \mathrm{PO}_{4}$. Batch adsorption of phenol from aqueous solution was investigated. The adsorptive properties were studied in terms of $\mathrm{pH}$, equilibrium time, initial concentration $\left(\mathrm{C}_{0}: 25-300 \mathrm{mg} / \mathrm{L}\right)$ and particle sizes $(0.125-1.6 \mathrm{~mm})$ effects. The experimental kinetic data fitted well the pseudo second order model and the equilibrium isotherm data the Langmuir model. The results indicate that chemical olive stones activated carbon is suitable to be used as an adsorbent material for adsorption of phenol from aqueous solution.
\end{abstract}

Keywords: Adsorption; Olive stones; Activated carbon; Phenol

\section{Introduction}

Phenol and its derivatives are toxic and carcinogenic in nature and are among the priority pollutants of the European Union and US Environmental Protection Agency [1]. Several methods, such as microbial degradation, adsorption, chemical oxidation, solvent extraction and reverse osmosis are being used for removing phenols from wastewater [2].

Activated carbons, the most important commercial adsorbents, are materials with large specific surface areas, high porosity, adequate pore size distributions and high mechanical strength [3,4]. Activated carbons can be produced from different carbonaceous materials such as coal, wood, peat and agricultural wastes especially lignocellulosic byproducts. They are widely employed in water and wastewater treatment processes for removing organic compounds such as phenol and its derivatives $[5,6]$.

Tunisia is classified in the fourth ranking of Mediterranean country in the production of olive oil. Therefore, olive trees cultivation constitutes a strategic position within the Tunisian agricultural sector, representing 1.6 million hectares under cultivation $(30 \%$ of agricultural land area) and counting an estimated 60 million olive trees [7]. This high production implies a big quantity of olive stone waste. In a previous work [8], olive stones were used to prepare an activated carbon by chemical processes using $\mathrm{H}_{3} \mathrm{PO}_{4}$ (COSAC). This precursor is a by-product of oleic factories producing olive oil in Tunisian country. The produced activated carbon is characterized by a high surface area, developed micropores and heterogeneous functional groups.

The aim of this study was to investigate kinetics and equilibrium aspects of the adsorption of phenol onto olive stones activated carbon. Three kinetics models including pseudo-first order, pseudosecond order and intra-particle diffusion models were used to discuss adsorption mechanisms. Experimental equilibrium isotherms were fitted with Langmuir and Freundlich equations to analyze the adsorption process.

\section{Materials and Experimental Methods}

\section{Activated carbon}

Preparation: Activated carbon was prepared from olive stones by chemical activation with orthphosphoric acid $\left(\mathrm{H}_{3} \mathrm{PO}_{4}\right)$ according to the method developed by Gharib et al. [8]. Initially, the precursor was washed thoroughly with water, dried and then impregnated with a dilute phosphoric acid solution for 9 hours at $110^{\circ} \mathrm{C}$. The resulting materials were washed with distilled water to remove any leachable impurities. The dried solid was carbonized in a vertical tubular fixed bed reactor heated at controlled temperature by electric furnace and fed with a continuous nitrogen flow. The carbonization time and temperature were optimized to be $2 \mathrm{~h} 30 \mathrm{~min}$ and $410^{\circ} \mathrm{C}$ respectively. The producer of carbon was washed with distilled water and then dried to be ready for using.

\section{Characterization of the activated carbon:}

a. Specific surface area and textural proprieties: Specific surface area and pores characteristics of activated carbon were determined by nitrogen adsorption and desorption isotherms at $77.7 \mathrm{~K}$ with an automatic Sorptiometer Autosorbe-1C Quantachrome apparatus (Common Services Research Unit of ENIG). The activated carbon sample is previously out gassed at $250^{\circ} \mathrm{C}$ and under vacuum. The micropores volume is estimated from nitrogen isotherm by analyzing the nitrogen adsoprtion isotherm at $77 \mathrm{~K}$ by Dubinin and Radushkevich micropore analysis method. The total pore volume is estimated from the adsorption quantity of nitrogen at relative pressure near unity. The measured values of textural characteristics are reported in Table1, we note the important micropore volume and a high specific surface area.

b. Determination of $\mathbf{p H}_{\mathrm{pzc}}$ : The point of zero charge ( $\mathrm{pHPZC)}$, $\mathrm{pH}$ at which the adsorbent is neutral in aqueous suspension, was determined following the procedure of Lopez-Ramon [9]. In this method $50 \mathrm{ml}$ of $0.01 \mathrm{M} \mathrm{NaCl}$ solutions were filled in closed Erlenmeyer

*Corresponding author: Thouraya Bohli, Laboratory of Research: Engineering Processes and Industrials Systems (LR11ES54), National School of Engineers of Gabes, University of Gabes, St Omar Ibn Elkhattab, 6029 Gabes, Tunisia, E-mail: bohli_th@yahoo.fr

\section{Received April 22, 2013; Accepted June 28, 2013; Published July 02, 2013}

Citation: Bohli T, Fiol N, Villaescusa I, Ouederni A (2013) Adsorption on Activated Carbon from Olive Stones: Kinetics and Equilibrium of Phenol Removal from Aqueous Solution. J Chem Eng Process Technol 4: 165 doi: 10.4172/21577048.1000165

Copyright: (c) 2013 Bohli T, et al. This is an open-access article distributed under the terms of the Creative Commons Attribution License, which permits unrestricted use, distribution, and reproduction in any medium, provided the original author and source are credited. 


\begin{tabular}{|c|c|}
\hline PARAMETERS & VALUE \\
\hline Apparent specific weight $\left(\mathrm{g} / \mathrm{cm}^{3}\right)$ & 0.55 \\
\hline Specific surface area $\mathrm{BET}\left(\mathrm{m}^{2} / \mathrm{g}\right)$ & 1040 \\
\hline Micropores volume $\left(\mathrm{cm}^{3} / \mathrm{g}\right)$ & 0.463 \\
\hline Mesopores volume $\left(\mathrm{cm}^{3} / \mathrm{g}\right)$ & 0.014 \\
\hline Total pore volume $\left(\mathrm{cm}^{3} / \mathrm{g}\right)$ & 0.477 \\
\hline Average pores diameter $(\mathrm{nm})$ & 1.835 \\
\hline $\mathrm{pH}_{\mathrm{pzc}}$ & 3.00 \\
\hline
\end{tabular}

Table 1: Physical and chemical characteristic of olive stones activated carbon.

flasks under agitation at room temperature of about $25^{\circ} \mathrm{C}$. The $\mathrm{pH}$ of each solution is initially fixed at value lying from 2 to 12 by adding $0.1 \mathrm{M} \mathrm{HCl}$ or $0.1 \mathrm{M} \mathrm{NaOH}$ solutions. Then $0.1 \mathrm{~g}$ of solid adsorbent was added to each flask and the final $\mathrm{pH}$ was measured after $48 \mathrm{~h} . \mathrm{pH}_{\mathrm{PZC}}$ is localized at the point where the curve $\mathrm{pH}_{\text {final }}$ versus $\mathrm{pH}_{\text {initial }}$ intersects the first bisector. The fined value is $\mathrm{pHpzc}=3$, showing that the activated carbon is anionic.

\section{Phenol}

Analytical-reagent grade phenol (purity $>99 \%$ ), was used as the adsorbate. A stock solution was prepared by dissolving required amount of phenol in double distilled water. Different initial concentrations $\left(\mathrm{C}_{0}\right)$ of phenol, in the range of $25-300 \mathrm{mg} / \mathrm{l}$, were obtained by successive dilutions.

Phenol concentration was determined by UV absorption at $270 \mathrm{~nm}$ wave-length using a calibrated UV-Visible spectrophotometer.

\section{Isotherm equilibrium adsorption construction}

Experiments were carried out by dispersing known quantities of adsorbent (0.1- $0.5 \mathrm{~g}$ ) within $200 \mathrm{ml}$ of $400 \mathrm{mg} / \mathrm{l}$ phenol solution in $250 \mathrm{ml}$ flasks. Adsorption equilibrium isotherms were measured via batch mode adsorption technique by placing volumetric flasks in a shaking mixer and using a thermostatic bath to control and to fix the temperature at $40^{\circ} \mathrm{C}$. After $48 \mathrm{~h}$ of mixing at fixed instant speed of 500 $\mathrm{rpm}$, samples were taken out from each flask and filtered. Initial and residual concentrations of phenol were measured using previously calibrated UV absorption at $270 \mathrm{~nm}$ analytical method.

For $\mathrm{pH}$ effect experimental study, the adsorption of phenol by COSAC was investigated over a $\mathrm{pH}$ range of 2 to 9 at $40^{\circ} \mathrm{C}$ with an initial solute concentration of $100 \mathrm{mg} / \mathrm{l}$ and an adsorbent carbon dose of $0.1 \mathrm{~g}$. Experiments were carried out for $48 \mathrm{~h}$ at constant agitation speed of $500 \mathrm{rpm}$. Initial solution $\mathrm{pH}$ was adjusted by adding a diluted $0.1 \mathrm{M} \mathrm{HCl}$ or $0.1 \mathrm{M} \mathrm{NaOH}$.

\section{Kinetics adsorption}

Kinetic adsorption was studied at various initial phenol concentrations $(25-300 \mathrm{mg} / \mathrm{l})$ and for different activated carbon particle sizes $(0.125-1.600 \mathrm{~mm})$ and the same quantity: $1.6 \mathrm{~g}$ in batch mixed suspension with $800 \mathrm{ml}$ of phenol solution at given initial concentration. The temperature of the suspension was maintained constant at $40{ }^{\circ} \mathrm{C}$ by using a thermostatic bath. Samples of $5 \mathrm{ml}$ were withdrawn at regular times and the residual phenol in the filtrates was measured.

The amount of phenol adsorbed on activated carbon $\mathrm{q}_{\mathrm{t}}(\mathrm{mg} / \mathrm{l})$ was followed versus time and was calculated using the following equation:

$$
q_{t}=\frac{\left(C_{O}-C_{t}\right) V}{m},(\mathrm{mg} / \mathrm{g})
$$

Where $\mathrm{C}_{0}$ and $\mathrm{C}_{t}$ are the concentration of phenol solution $(\mathrm{mg} / \mathrm{l})$ at initial and at sampling time $(\mathrm{t})$ respectively; $\mathrm{V}$ the volume of solution (l) and $\mathrm{m}$ is the weight ( $\mathrm{mg}$ ) of activated carbon. Each experiment was carried out in duplicated way and the average results are presented in this work.

\section{Results and Discussion}

\section{Effect of initial $\mathrm{pH}$ on the adsorption}

The $\mathrm{pH}$ of solution is one of the most important parameter affecting phenol adsorption processes because it affects the surface charge of the adsorbent as well as the degree of ionization and speciation of phenol [10]. Effect of initial $\mathrm{pH}$ on adsorption of phenol was studied with initial concentration of $100 \mathrm{mg} / \mathrm{l}$ and optimum carbon dose of $1 \mathrm{~g} / \mathrm{l}$ and at a temperature of $40^{\circ} \mathrm{C}$. Figure 1 shows the influence of solution $\mathrm{pH}$ on phenol removal by COSAC in the $\mathrm{pH}$ range of 2.0 to 9.0. The phenol adsorption decreases slowly with the increase of $\mathrm{pH}$ for values up than $\mathrm{pH}=4.0$ and the adsorption sharply decreases for $\mathrm{pH}>6$. The maximum phenol uptake obtained at $\mathrm{pH}$ lower than pHpzc $(\mathrm{pHpzc}=3)$ can be explained by the fact that at this $\mathrm{pH}$ range the COSAC surface is charged positively and phenol was protonated [11] this create a strong electrostatic interaction between phenol molecule carbon surface. However, with the increase of $\mathrm{pH}$ solution behind $\mathrm{pHpzc}$, phenol become more and more dissociated and COSAC surface is charged more negatively leading to increased electrostatic repulsion force between the anionic phenol form and $\mathrm{OH}$ - groups on COSAC surface and between phenolate-phenolate anions in solution [12] resulting in a decrease of phenol uptake. Taking into account the obtained results further experiments were carried out at $\mathrm{pH} 2.3$ without adjustment.

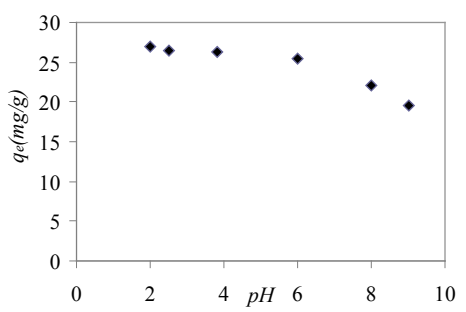

Figure 1: Effect of $\mathrm{pH}$ on the uptake of phenol onto COSAC (Temperature $313 \mathrm{~K}$, initial concentration $100 \mathrm{mg} / \mathrm{l}$ )
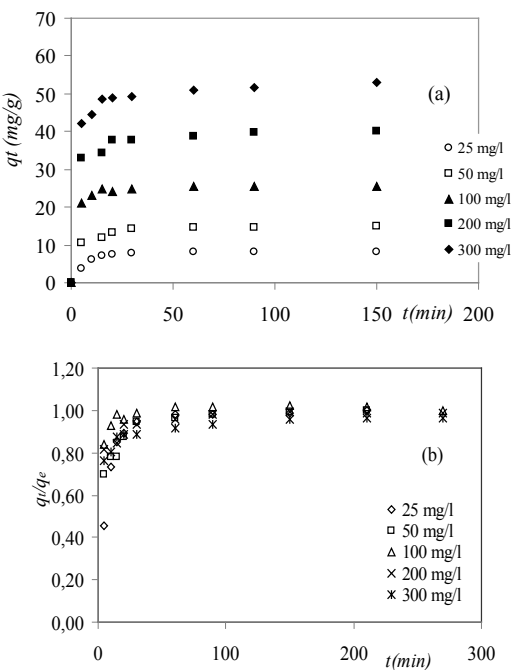

Figure 2: Initial concentration effect on process kinetics for the adsorption of phenol onto COSAC (Particle sizes: $0.630-1.000 \mathrm{~mm}$, temperature 313 $\mathrm{K}$, initial $\mathrm{pH}: 2.3$ ). 


\section{Effect of contact time and initial concentration}

Initial concentration effect on the removal of phenol is reported in Figure 2a. When initial phenol concentration increased from 25 to $300 \mathrm{mg} / \mathrm{l}$, the adsorption capacity of COSAC increased from 8 to 53 $\mathrm{mg} / \mathrm{g}$. The time evolution of the amount adsorbed phenol indicates that the equilibrium time was reached at about $60 \mathrm{~min}$ for all the initial concentrations (Figure $2 \mathrm{~b}$ ). We observe two kinetics regions: the first one is characterized by a high adsorption rate and this is due to that initially the number of sites of activated carbon available is higher and the driving force for the mass transfer is greater. Therefore, phenol reaches the adsorption site easily. As time progress the number of free site of COSAC decreases and the non adsorbate molecules are assembled at the surface thus limiting the capacity of adsorption. The increase of loading capacities of COSAC with increasing phenol concentration may be due to higher $\pi-\pi$ interaction between phenol and the surface function of activated carbon. $\pi-\pi$ interaction is usually the mean involved mechanism of phenol adsorption $[13,14]$.

\section{Effect of the particle size on the adsorption kinetic of phenol}

The amount adsorbed phenol extent versus the agitation time for different particles sizes $(0.125-1.6 \mathrm{~mm})$ at the same phenol initial concentration of $100 \mathrm{mg} / \mathrm{l}$, natural $\mathrm{pH}$ (around 2.3) and an stirrer speed of $500 \mathrm{rpm}$ are shown in Figure 3. This high mixing speed was considered to be sufficient to overcome the external film diffusion resistance. Results show that: the smaller the particle size, the faster was the adsorption kinetic. We can also observe, for all particle sizes, that the adsorption processes could be subdivided in two steps: rapid first one followed by a slow step, this is become evident for small particle size. By else, with increasing particle size the phenol adsorption quantity decreases and the kinetic is slower. This confirms the hinting effect of the internal mass transfer process in the dynamic of the adsorption process

Figure 3 suggests that there are two linear sections in each plot. The first section corresponds to the diffusion in the micropores. At the beginning of the phenol diffusion into COSAC, there is a fast initial uptake (part 1) with high intraparticle diffusion rate constant. It accounts for approximately $91 \%$ of the overall adsorption capacity for a particle size between 0.63 and $1 \mathrm{~mm}$.

The first rapid step is due to a high interaction between adsorbent surface and phenol (sites with high affinity). The second step is relative to a less energetic adsorption with carbon sites having low affinity and formation of multilayer.

\section{Adsorption kinetics}

Pseudo-first-order, pseudo-second-order and intra particular

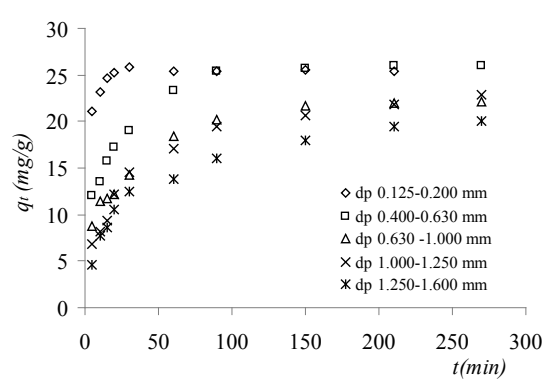

Figure 3: Effect of contact time on the amount of phenol onto COSAC for different particle size, (initial concentration of $100 \mathrm{mg} / \mathrm{L}$, temperature $313 \mathrm{~K}$, initial $\mathrm{pH}$ of 2.3). diffusion models are applied to describe the kinetic data. The effect of initial concentration and particle sizes was investigated to find the best kinetic model.

Pseudo-first order model: The pseudo-first-order of Lagergren [15] is expressed in a linear form:

$$
\operatorname{Ln}\left(q_{e}-q_{t}\right)=k_{1} t+\operatorname{Ln} q_{e}
$$

Where $k_{1}$ is the rate constant of pseudo-first order adsorption $\left(\mathrm{mn}^{-1}\right)$, $q_{t}$ and $q_{e}$ are respectively the instantaneous and equilibrium amount of phenol adsorption per unit weight of activated carbon $(\mathrm{mg} / \mathrm{g})$ and $\mathrm{t}$ is the time ( $\min )$. The plot of $\operatorname{Ln}\left(q_{e}-q_{t}\right)$ versus $t$ should give a linear relationship with the slope equal to: $k_{1}$.

Results given in Table 2 indicate that first order kinetic model does not correctly fit the experimental data for different initial concentration and particle sizes; coefficients regression are between 0.598 and 0.920 and the phenol uptakes are less then these given by experiment.

Pseudo-second order model: The kinetic data are fitted with pseudo-second order model resulting in the following linear equation [16]:

$$
\frac{t}{q}=\frac{1}{K_{2} q_{e}}+\frac{1}{q_{e}} t
$$

Where $K_{2}$ is the rate constant of pseudo-second order.

The linear plots of $t / q_{t}$ versus $t$ show that the experimental data agree with the pseudo-second order kinetic model. The calculated $q$ $(\mathrm{mg} / \mathrm{g})$ (Table 2) values agree very well with the experimental data and the correlation coefficients close to the unit in all cases. These indicate that the adsorption of phenol from aqueous solution on COSAC obey the pseudo-second order kinetic model. It was observed also that the constant kinetic, $k_{2}$, decreased with the increasing of the initial phenol concentration and particles size. This shows the importance of transport process, particularly the internal diffusion in overall adsorption process kinetics some observations are reported by Srihari et al. [16].

Intra-particle diffusion: Intra-particle diffusion was often considered as the limiting step which limits the kinetics in the most process of adsorption. The possibility of a limitation by the diffusion in the pores is explored by plotting phenol uptake against the square root of time, using the Weber and Morris model:

$$
q_{t}=k_{d} \sqrt{t}+C
$$

Where $q_{t}$ is the instantaneous amount of phenol adsorption per unit gram of activated carbon $(\mathrm{mg} / \mathrm{g}), \mathrm{C}(\mathrm{mg} / \mathrm{g})$ is a constant giving an idea about the thickness of the boundary layer: the larger the value of $\mathrm{C}$ is more important the lay effect limitation.

The intraparticle diffusion model plots for the adsorption of phenol onto COSAC, under the effect of initial phenol concentration and carbon particle size, suggest that there are two linear parts in each plot. The initial parts are attributed to boundary layer diffusion effects or external mass transfer effects. These lines do not pass through the origin indicating that the intra-particle diffusion is not the only process that can control kinetics of adsorption [16,17]. Whereas, the second parts may be attribute to intra-particle diffusion effects.

The rate constants: $\mathrm{k}_{\mathrm{d} 1}$ and $\mathrm{k}_{\mathrm{d} 2}$, of intraparticle diffusion $(\mathrm{mg} / \mathrm{g})$, was calculated respectively from the slope of the first and second linear portion of the plots. It is obvious from Table 2 that $\mathrm{k}_{\mathrm{d} 1}$ is higher than $\mathrm{K}_{\mathrm{d} 2}$. This can be related to the fact that firstly the number of pores available are very high and after there is possibility of pore blockage 
Citation: Bohli T, Fiol N, Villaescusa I, Ouederni A (2013) Adsorption on Activated Carbon from Olive Stones: Kinetics and Equilibrium of Phenol Removal from Aqueous Solution. J Chem Eng Process Technol 4: 165 doi:10.4172/2157-7048.1000165

or steric hindrance exerted by the adsorbed molecules on the carbon surface, it will eventually slow down the adsorption process and give rise to other linear sections with smaller intraparticle rate constants.

The validity of the order of adsorption processes is based on the regression coefficients and on predicted $q_{e}$ values. Table 2 shows that correlation coefficients of the pseudo-second order kinetic model are the highest as compared to these given by the pseudo-first order and interparticle diffusion model. Either the $q_{e}(\mathrm{mg} / \mathrm{g})$ calculated by the pseudo-second order, agree very well with the experimental data. Thus indicate that the adsorption of phenol from aqueous solution on COSAC obey the pseudo-second order kinetic model.

\section{Isotherm of adsorption}

The adsorption isotherm of phenol on COSAC was studied at $30^{\circ} \mathrm{C}$ and an initial solution $\mathrm{pH}$ of 2.3 . As can be seen from Figure 4 [18] and according to the classification of Brunauer, Emett, and Teller the adsorption isotherm of phenol on CACOS is of type IV shows the formation of two successive layers of phenol on the surface of activated carbon when the interactions between the molecules of phenol and the surface of adsorbent are stronger than the interactions between the adsorbed molecules. In this case, the sites of adsorption of the second layer begin to fill perform only when the first layer is complete.

The same shape of isotherm was found by Calace et al. [19], when they study the adsorption 4-nitrophenol (4-NP) on papermill sludges.

The first part of the equilibrium experimental isotherm was modeled by Langmuir and Freundlich equations (Figure 5). According to the theory of adsorption, the model of Langmuir is based on the fixation of a monolayer of adsorbate molecules on the surface of pores. The model assumes uniform adsorption on the surface and no transmigration in the plane of the surface. Langmuir's equation is mathematical expressed as follows.

$$
q_{e}=\frac{q_{\max } K_{L} C_{e}}{1+K_{L} C_{e}}
$$

Where: $K_{L}$ is the equilibrium adsorption constant related to the free energy of the adsorption $(1 / \mathrm{mg})$ and $q_{\text {max }}$ : the maximum adsorption capacity $(\mathrm{mg} / \mathrm{g}), C_{e}$ the equilibrium concentration $(\mathrm{mg} / \mathrm{l})$, is the $q_{e}$ amount adsorbed at equilibrium (mg/g). The linear form of equation (5) is given equation (6):

$$
\frac{C_{e}}{q_{e}}=\left(\frac{1}{q_{\max } K_{L}}\right)+\left(\frac{1}{q_{\max }}\right) C_{e}
$$

The essential characteristics of Langmuir model can be expressed by dimensionless constant called separation factor, $R_{L}$, with is given by this equation:

$$
R_{L}=\frac{1}{1+K_{L} C_{0}}
$$

The adsorption is considered as irreversible $R_{L}=0$, favourable when $0<\mathrm{R}_{\mathrm{L}}<1$, linear when $\mathrm{R}_{\mathrm{L}}=1$ and unfavourable when $\mathrm{R}_{\mathrm{L}}>1$.

The Freundlich equation is an empirical model that considers heterogeneous adsorptive energies on the adsorbent surface [15].

$$
q_{e}=K_{F} C^{1 / n}
$$

The linear form of equation (8) is given equation (9):

$$
\log q_{e}=\log K_{F}+\frac{1}{n} \log C_{e}
$$

Where, $K_{F}(1 / \mathrm{g})$ and $1 / n$ are Freundlich constants. The parameters of both models are calculated and summarized in Table 3 .

Figure 5 shows that Langmuir equation is more reasonably applicable than Freundlich equation with correlation coefficients $\mathrm{R}^{2}$ equal to 0.99 and an $\mathrm{R}_{\mathrm{L}}$ of 0.061 indicating favourable adsorption of phenol on COSAC.

Ozkaya [20] studied the removal of phenol using a commercial activated carbon, Langmuir adsorption model give a maximum uptake of $49.7 \mathrm{mg} / \mathrm{g}$. Srivastava et al. [15], were studied the adsorptive removal of phenol by bagasse fly ash (BFA) and two activated carbons ACC and ACL, maximums amount given by Langmuir model are respectively $23.83,30.22$ and $24.65 \mathrm{mg} / \mathrm{g}$. Kilic et al. [21], investigated phenol adsorption from aqueous solutions by activated carbon prepared from

\begin{tabular}{|c|c|c|c|c|c|c|c|c|c|c|}
\hline & \multicolumn{3}{|c|}{ First order $\mathrm{k}_{1}\left(\mathrm{~min}^{-1}\right) \mathrm{q}_{\mathrm{e}}(\mathrm{mg} / \mathrm{g}) \mathrm{R}^{2}$} & \multicolumn{3}{|c|}{ second order $k_{2}\left(\min ^{-1}\right) q_{e} R^{2}$} & \multicolumn{4}{|c|}{ intra-particle diffusion $k_{d 1}(m g / g) R^{2} k d_{2}(m g / g) R^{2}$} \\
\hline \multicolumn{11}{|c|}{ Initial concentration (mg/L) } \\
\hline 25 & 0.0627 & 4.525 & 0.889 & 1.9847 & 25.575 & 1 & 1.6359 & 0.936 & 0.0675 & 0.7864 \\
\hline 50 & 0.0544 & 9.387 & 0.734 & 0.1045 & 27.100 & 0.999 & 1.1192 & 0.929 & 0.0937 & 0.9512 \\
\hline 100 & 0.1743 & 13.538 & 0.784 & 0.0698 & 23.419 & 0.998 & 1.4511 & 0.813 & 0.0194 & $\alpha$ \\
\hline 200 & 0.0423 & 13.279 & 0.641 & 0.0493 & 24.038 & 0.998 & 1.8901 & 0.747 & 0.1822 & 0.7535 \\
\hline 300 & 0.0384 & 15.825 & 0.598 & 0.0468 & 21.276 & 0.997 & 3.2479 & 0.952 & 0.3152 & 0.8573 \\
\hline \multicolumn{11}{|c|}{ Particle size $(\mathrm{mm})$} \\
\hline $0.125-0.2$ & 0.1401 & 10.479 & 0.814 & 0.2104 & 8.803 & 0.996 & 1.464 & 0.915 & 0.0426 & $\alpha$ \\
\hline $0.4-0.63$ & 0.0341 & 18.541 & 0.935 & 0.3257 & 15.240 & 0.999 & 2.091 & 0.992 & 0.2557 & $\alpha$ \\
\hline $0.63-1$ & 0.0253 & 16.629 & 0.920 & 0.5509 & 25.773 & 1 & 1.535 & 0.926 & 0.4246 & 0.867 \\
\hline $1-1.25$ & 0.0226 & 17.101 & 0.923 & 0.5560 & 40.322 & 0.999 & 2.481 & 0.961 & 0.0613 & 0.957 \\
\hline $1.25-1.6$ & 0.0275 & 17.995 & 0.920 & 0.6428 & 52.631 & 1 & 2.386 & 0.984 & 0.7051 & 0.960 \\
\hline
\end{tabular}
tobacco residues, results show that maximums removal are 17.83 and $0.55 \mathrm{mg} / \mathrm{g}$ respectively for ACK1 and ACK2. In the present work, Table 2 shows a maximum uptake related to the first part of phenol isotherm of $58.82 \mathrm{mg} / \mathrm{g}$ and Figure 2 give an experimental value of the amount

$\alpha$ : for values less than 0.7

Table 2: Kinetic parameters for the adsorption of phenol onto COSAC.

\begin{tabular}{|c|c|c|c|c|c|c|}
\hline \multicolumn{4}{|c|}{ Langmuir parameters } & \multicolumn{2}{c|}{ Freundlich parameters } \\
\hline $\mathrm{q}_{\max }(\mathrm{mg} / \mathrm{g})$ & $\mathrm{K}_{\mathrm{L}}(\mathrm{l} / \mathrm{mg})$ & $\mathrm{R}_{\mathrm{L}}$ & $\mathrm{R}^{2}$ & $\mathrm{~K}_{\mathrm{F}}(\mathrm{L} / \mathrm{g})$ & $\mathrm{R}$ \\
\hline 58.823 & 0.038 & 0.061 & 0.99 & 3.935 & 1.865 \\
\hline
\end{tabular}

Table 3: Langmuir and Freundlich sorption parameters. 
Citation: Bohli T, Fiol N, Villaescusa I, Ouederni A (2013) Adsorption on Activated Carbon from Olive Stones: Kinetics and Equilibrium of Phenol Removal from Aqueous Solution. J Chem Eng Process Technol 4: 165 doi:10.4172/2157-7048.1000165

Page 5 of 5

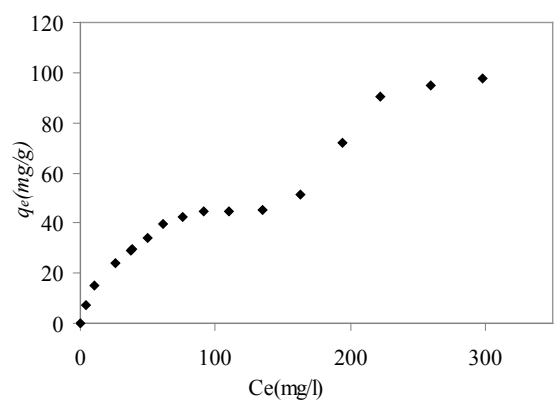

Figure 4: Experimental adsorption isotherms of phenol onto COSAC (temperature: $313 \mathrm{~K}$, initial $\mathrm{pH}: 2.3$, particle size: $0.630-1.000 \mathrm{~mm}$ )

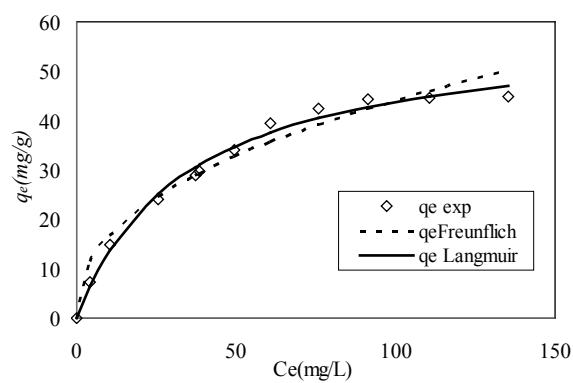

Figure 5: Comparison of experimental and predicted adsorption isotherms of phenol onto COSAC according to Langmuir and Freundlich models for the first part (temperature $313 \mathrm{~K}$, initial $\mathrm{pH} 2.3$, particle size: $0.630-1.000 \mathrm{~mm}$ ).

uptake related to the second part of this isotherm of about $97.6 \mathrm{mg} / \mathrm{g}$. These results indicate that COSAC can be consider as a good adsorbent of phenol as compared by other materials for removing phenol, COSAC shows a high capacity to sorbs this pollute from water.

\section{Conclusion}

In this study, the adsorption of phenol from aqueous solution using olive stones activated carbon (COSAC) was investigated. Results indicate that adsorption capacity of COSAC was considerably affected by $\mathrm{pH}$, initial concentration, and particle size. Phenol adsorbent increased with increasing initial concentration and decrease with the increase of particle size of activated carbon.

Kinetic experiments carried out with different particle sizes of COSAC showed that the smaller the particle size, the faster was the diffusion of phenol into adsorption sites of adsorbent. Kinetics results of phenol adsorption were examined using the pseudo-first-order, pseudo-second-order and intra particular diffusion kinetics models. The results obtained show that the pseudo-second order model was the best to describe adsorption kinetic data for phenol. Equilibrium data were fitted to Langmuir and Freundlich isotherms and the best fit was given by the Langmuir isotherm model, with a maximum monolayer adsorption capacity of about $58.8 \mathrm{mg} / \mathrm{g}$. thus indicates that COSAC is suitable to be used as an adsorbent material for adsorption of phenol from aqueous solution it may also be effective in removing other harmful species such as heavy metals.

\section{References}

1. Santana CM, Ferrera ZS, Torres Padrón ME, Santana Rodríguez JJ (2009) Methodologies for the Extraction of Phenolic Compounds from Environmental Samples: New Approaches. Molecules 14: 298-320.

2. Liu QS, Zheng T, Wang P, Jiang JP, Liu N (2010) Adsorption isotherm, kinetic and mechanism studies of some substituted phenols on activated carbon fibers. Chemical Engineering Journal 157: 348-356.

3. Ugurlu M, Gurses A, Acikyildiz M (2008) Comparison of textile dyeing effluent adsorption on commercial activated carbon and activated carbon prepared from olive stones by $\mathrm{ZnCl} 2$ activation. Microporous and Mesoporous Materials 111: 228-235.

4. Mohanty K, Das D, Biswas MN (2005) Adsorption of phenol from aqueous solutions using activated carbons prepared from Tectona grandis sawdust by $\mathrm{ZnCl} 2$ activation. Chemical Engineering Journal 115: 121-131.

5. Baudu M, Guibaud G, Raveau D, Lafrance P (2001) Prediction of adsorption from aqueous phase of organic molecules as a function of some physicochemical characteristics of activated carbons. Water Quality Research Journal of Canada 36: 631-657.

6. Ania CO, Parra JB, Pis JJ (2008) Effect of texture and surface chemistry on adsorptive capacities of activated carbons from phenolic compounds removal. Fuel Processing Technology 78: 337-343.

7. Hannachi H, Msallem M, Elhadj SB, El Gazzah M (2007) Influence du site géographique sur les potentialités agronomiques et technologiques de l'olivier (Olea europaea L.) en Tunisie. Comptes Renduus Biologies 330: 135-142.

8. Ouederni A, Gharib H (2005) Processing olive pomace Tunisian activated carbon chemically with phosphoric acid. Recent Advances in Process Engineering, SFGP, Paris, France.

9. Lopez-Ramon MV, Stoeckli F, Moreno-Castilla C, Carrasco-Marin F (1999) On the characterization of acidic and basic surface sites on carbons by various techniques. Carbon 37: 1215-1221.

10. Maleki A, Mahvi AH, Ebrahimi R, Khan J (2010) Evolution of Barley straw and its Ash in Removal of Phenol from Aqueous System. Word Applied Sciences Journal 8: 369-373.

11. Lü G, Hao J, Liu L, Ma H, Fang Q, et al. (2011) The Adsorption of Phenol by Lignite Activated Carbon. Chinese Journal of Chemical Engineering 19: 380-385.

12. Mareno-Castilla C (2004) Adsorption of organic molecules from aqueous solutions on carbon materials. Carbon 42: 83-94.

13. Li D, Wu Y, Feng L, Zhang L (2012) Surface properties of SAC and its adsorption mechanisms for phenol and nitrobenzene. Bioresource Technology 113: $121-126$.

14. Li Y, Du Q, Liu T, Peng X, Wang J, et al. (2013) Comparative study of methylene blue dye adsorption onto activated carbon, graphene oxide, and carbon nanotubes. Chemical Engineering Research and Design 91: 361-368. 15.

15. Srivastava VC, Swamy MM, Mall ID, Prasad B, Mishra IM (2006) Adsorptive removal of phenol by bagasse fly ash and activated carbon: Equilibrium kinetics and thermodynamics. Colloids and Surfaces A: Physicochemical Engineering Aspects 272: 89-104.

16. Srihari V, Das A (2008) The kinetic and thermodynamic studies of phenolsorption onto three agro-based carbons. Desalination 255: 220-234.

17. Hall KR, Eagleton LC, Acrivos A, Vermeulen T (1996) Pore-and solid-diffusion kinetics in fixed-bed adsorption under constant-pattern conditions. Industrial \& Engineering Chemistry Fundamentals 5: 212-223.

18. Khalfaoui M, Knani S, Hachicha MA, Ben Lamine A (2003) New theoretica expressions for the five adsorption type isotherms classified by BET based on statistical physics treatment. J Colloid Interface Sci 263: 350-356.

19. Calace N, Nardi E, Petronio BM, Pietroletti M (2002) Adsorption of phenols by papermill sludges. Environmental Pollution 118: 315-319.

20. Ozkaya B (2006) Adsorption and desorption of phenol on activated carbon and a comparison of isotherm models. Journal of Hazardous Materials 129: 158-163.

21. Kilic M, Apaydin-Varol E, Pütün AE (2011) Adsorptive removal of phenol from aqueous solutions on activated carbon prepared from tobacco residues: Equilibrium, kinetics and thermodynamics. Journal of Hazardous Materials 189: 397-403.

Citation: Bohli T, Fiol N, Villaescusa I, Ouederni A (2013) Adsorption on Activated Carbon from Olive Stones: Kinetics and Equilibrium of Phenol Removal from Aqueous Solution. J Chem Eng Process Technol 4: 165 doi: 10.4172/2157-7048.1000165 